\title{
Role of Low Ankle-Brachial Index in Cardiovascular and Mortality Risk Compared with Major Risk Conditions
}

\author{
Lia Alves-Cabratosa ${ }^{1}$, Maria Garcia-Gil ${ }^{1}$, Marc Comas-Cufí ${ }^{1}$, Jordi Blanch ${ }^{1} \oplus$, Anna Ponjoan ${ }^{1,3}$, \\ Ruth Martí-Lluch 1,3, Marc Elosua-Bayes ${ }^{1}$, Dídac Parramon ${ }^{1,4}$, Lourdes Camós ${ }^{1,4}$ and \\ Rafel Ramos 1,2,3,4,* \\ 1 Vascular Health Research Group of Girona (ISV-Girona), Fundació Institut Universitari d'Investigació en \\ Atenció Primària Jordi Gol (IDIAP Jordi Gol), 17002 Girona, Spain; lalves@idiapjgol.info (L.A.-C.); \\ mgarcia@idiapjgol.info (M.G.-G.); mcomas@idiapigol.info (M.C.-C.); jblanch@idiapigol.info (J.B.); \\ aponjoan@idiapjgol.info (A.P.); rmarti.girona.ics@gencat.cat (R.M.-L.); melosua@idiapjgol.info (M.E.-B.); \\ dparramont.girona.ics@gencat.cat (D.P.); lourdes5d8@gmail.com (L.C.) \\ 2 Department of Medical Sciences, School of Medicine, University of Girona, 17003 Girona, Spain \\ 3 Institut d'Investigació Biomèdica de Girona (IDIBGI), 17190 Girona, Spain \\ 4 Primary Care Services, Girona, Catalan Institute of Health (ICS), 17001 Girona, Spain \\ * Correspondence: rramos.girona.ics@gencat.cat; Tel.: +34-972-487968; Fax: +34-972-214100
}

Received: 17 May 2019; Accepted: 17 June 2019; Published: 18 June 2019

\begin{abstract}
Cardiovascular prevention is of particular interest in persons with asymptomatic peripheral arterial disease. We aimed to quantify its association with mortality and cardiovascular outcomes, compared to other indicators of high risk. We performed a retrospective cohort study using the Database of the Catalan primary care system (SIDIAPQ ${ }^{\mathrm{Q}}$ ), for 2006-2015, including 35-85-year-old patients with an ankle-brachial index (ABI) measurement, classified according to the presence of diabetes, cardiovascular disease, and low ABI $(<0.9)$. We calculated the incidences and hazard ratios (HRs) for all-cause mortality, acute myocardial infarction, and ischemic stroke. During a median follow-up of 5.9 years, we analyzed 58,118 persons. The mean (SD) age was 66.6 (10.7) years and $53.4 \%$ were men. Compared to the reference group with no diabetes, no previous cardiovascular disease, and normal ankle-brachial index, the HR for all-cause mortality was $1.42(1.25-1.63)$ in the group with low ABI, 1.35 (1.26-1.45) in those with diabetes, 1.50 (1.34-1.69) in those with previous cardiovascular disease, and $1.84(1.68-2.01)$ in those with low ABI and diabetes. In conclusion, participants with low ABI showed increased mortality, acute myocardial infarction, and ischemic stroke incidence in all the subgroups. Patients with low ankle-brachial index plus diabetes presented increased mortality, acute myocardial infarction, and ischemic stroke risk, all at rates similar to those with previous cardiovascular disease.
\end{abstract}

Keywords: peripheral artery disease; diabetes; cardiovascular disease; ankle-brachial index; electronic health records

\section{Introduction}

Cardiovascular diseases (CVDs) remain a major cause of mortality despite improvements in their prevention and management [1,2]. Prevention of these diseases, a key factor in reducing their mortality and morbidity burden, is grounded in appropriate individual risk assessment [3]. In primary prevention candidates, cardiovascular risk is estimated using risk functions that integrate multiple interacting risk factors [4-6]. Some persons, including those with diabetes or previous CVD, are considered to be at high or very high cardiovascular risk without the need of a risk score, and require 
immediate attention to risk factors [7]. Yet another group, those with asymptomatic disease, is less defined: they have atherosclerosis, including peripheral arterial disease (PAD), but its expression is silent, although harmful, all the same [8]. This is a group of high interest because early detection of asymptomatic disease would allow immediate implementation of preventative measures [9].

Asymptomatic PAD can be detected with the ankle-brachial index (ABI), a first screening method after clinical examination [9]. The ABI is the ratio of the systolic blood pressure measured at the ankle to that measured at the brachial artery [8]. It is a simple office-based test with high availability, reproducibility, and cost-effectiveness [8], although it is not exempt from certain limitations [8], and it is readily available in primary care practices, which could be the optimal setting for the screening of this disease.

The presence of low ABI, defined as $<0.9$, has been proposed as a modifier of total cardiovascular risk [7]. This association has been assessed in general population, independently from the Framingham risk score [10]; in persons with diabetes [11,12]; and in persons with previous history of coronary artery disease, in addition to diabetes mellitus and traditional risk factors [13]. To date, no studies have examined the extent to which the impact of low ABI is affected by the simultaneous presence or absence of conditions known to increase risk, like diabetes and previous CVD.

Accordingly, we sought to compare the association of low ABI with mortality, acute myocardial infarction (AMI), and ischemic stroke (IS) in a variety of population subgroups according to the baseline presence or absence of diabetes and previous CVD.

\section{Methods}

\subsection{Data Source}

Data were obtained from the System for the Development of Research in Primary Care (SIDIAPQ). This is a database that contains longitudinal information on demographic data, clinical diagnoses coded according to the International Classification of Diseases-10th revision (ICD-10), referral and hospital discharge information coded using ICD-9, laboratory tests, and treatments (drug prescriptions and drug invoicing at any community pharmacy), at an individual and ecological level. Data are standardized, quality-controlled, anonymized, and structured for research purposes. Identifiers are encoded to ensure confidentiality of personal data of patients in the 274 Primary Care Practices (a total of 1365 general practitioners) managed by the Catalan Institute of Health throughout Catalonia. Completeness and continuity are externally assessed. Only records that meet pre-defined data quality standards are included in SIDIAPQ, which compiles information on nearly 2 million patients, yielding around 20 million person-years for the period 2005-2015. These high-quality data are representative of the geographical, age, and sex distributions of the population of Catalonia [14], particularly for cardiovascular risk factors and CVD [15], and have been widely used in epidemiological research [16-19]. Ethics approval to use SIDIAPQ data for observational research was obtained from the Ethics Committee for Clinical Research IDIAP Jordi Gol (P14/052).

\subsection{Study Design and Participants}

This retrospective cohort study included records of patients aged 35 to 85 years with an ABI measurement recorded in the SIDIAPQ database during the recruitment period between January 2006 and December 2011; the date of first ABI measurement defined study entry date. We included patients with normal $\mathrm{ABI}$ at entry, defined as $0.9 \leq \mathrm{ABI}<1.3$, or with low $\mathrm{ABI}$, defined as $\mathrm{ABI}<0.9$. We excluded data from persons with high $A B I$, defined as $A B I \geq 1.3$. ABI values can be high due to medial arterial calcification, especially in persons with diabetes, and this can concur with certain degree of atherosclerosis; thus, we considered this group should be studied separately concerning the purpose of this study, to avoid confusion [20]. To prevent inclusion of persons with symptomatic PAD, we also excluded persons with low ABI who additionally had (i) a prescription of any drug related to intermittent claudication (cilostazol, pentoxifylline, buflomedil, or naftidrofuryl); (ii) any symptom 
of intermittent claudication detected by thorough review of uncoded information in the attending physician's notes; or (iii) an ABI < 0.4, because a patient with such level of ABI would very likely be symptomatic. Finally, type I diabetes was an exclusion criterion.

Follow-up extended until an outcome occurred, and censoring applied to participants whose data were transferred out of the SIDIAPQ reference area or at the end of the study period, 31 December 2015. This guaranteed a minimum of 4 years of data for each participant.

\subsection{Exposure and Outcomes}

ABI records followed the official Primary Care Services protocol to standardize ABI measurements [9]. This protocol states that the systolic blood pressure has to be measured in each arm and each ankle just above the malleoli with Doppler probes. The higher value of the dorsalis pedis and the tibial posterior arteries of each leg is divided by the higher value of the systolic blood pressure of the arm. The resulting lower value is the ABI [8].

Participants who fulfilled inclusion criteria were classified into eight groups according to exposure at baseline, defined by $\mathrm{ABI}$ category and previous history of CVD and/or diabetes: (1) diabetes, prior CVD, and low ABI values; (2) diabetes and prior CVD, but normal ABI; (3) diabetes and low ABI; (4) prior CVD and low ABI; (5) prior CVD alone; (6) low ABI alone; (7) diabetes alone; (8) no diabetes, no prior CVD, and normal ABI (the reference group). Previous history of CVD included AMI, angina, stroke, and transient ischemic attack. Diabetes at baseline was defined with diagnosis of diabetes or treatment with drugs used in diabetes (coded as a10 in the Anatomical Therapeutic Chemical (ATC) Classification System). The outcomes assessed were all-cause mortality, AMI, and IS.

\subsection{Covariates}

We characterized the population and included potential modifiers of the low ABI association with all-cause mortality, AMI, and IS [5,21-26], describing age, sex, smoking habit, continuous variables: body mass index (BMI) -calculated as weight divided by squared height-, systolic and diastolic blood pressure (BP), pulse pressure, low (LDL) and high (HDL) density lipoprotein cholesterol, triglycerides; we considered the last record up to one year previous to entry date $(72 \%$ to $85 \%$ of the population had a record up to 6 months previous to entry date). We also described the following comorbidities: hypertension, atrial fibrillation, malignant neoplasms, chronic kidney disease, and chronic obstructive pulmonary disease. We considered the presence of a condition in a patient if such was recorded previously to entry date. Finally, we accounted for the following medications: diuretics, beta blocking agents, calcium channel blockers, agents acting on the renin-angiotensin system, statins, other lipid modifying agents, and aspirin. A person was defined as treated if they had a purchase record of a given medication up to 6 months previous to the entry date (87\% to $93 \%$ of the population had a purchase record up to 3 months previous to entry date).

\subsection{Statistical Analysis}

Continuous variables were expressed as mean and standard deviation (SD), or median (1st and 3rd quartiles); and categorical variables as percentages.

To avoid the potential selection bias that may occur when excluding participants with missing values [27], we performed multiple imputation by chained equations of the variables with missing values; we generated 50 imputation tables with 50 iterations each [28]. The population characteristics conceded plausibility to the missing-at-random assumption, and we also performed sensitivity analysis with the complete-case population [29] for comparison.

Raw incidence rates per 1000 person-years of all-cause mortality, AMI, and IS were calculated by exposure group. Cox proportional hazard models were used to analyze the adjusted association of low ABI values with all-cause mortality, AMI, and IS. For all outcomes, a set of candidate variables for adjustment was considered, based on the literature. Initially, we assessed the unadjusted association of the categories of exposure with each outcome. We then tested the association by including the 
categories of exposure and each candidate variable in the model. Both associations were compared using the standardized difference. We sequentially increased the number of adjusting variables by including the variable with the highest standardized difference. This greedy process was repeated until the standardized difference for the association when adding a candidate variable was lower than 0.10. All analyses were carried out using R-software [30] (version 3.5.1; R Foundation for Statistical Computing, Vienna, Austria), including MICE v2.15 package for multiple imputation [31].

\section{Results}

During the recruitment period, SIDIAPQ ${ }^{\mathrm{Q}}$ contained data of 69,069 individuals aged 35 to 85 years who had an ABI measurement, 58,118 of which fulfilled inclusion criteria (Figure 1); 41,297 (71.1\%) had diabetes, 11,812 (20.3\%) had previous CVD, and 10,684 (18.4\%) had low ABI. Median (1st quartile, 3rd quartile) follow-up for the whole study population was $5.9(4.7,7.6)$ years. Follow-up was lost for 914 individuals due to transfer from the SIDIAPQ reference area.

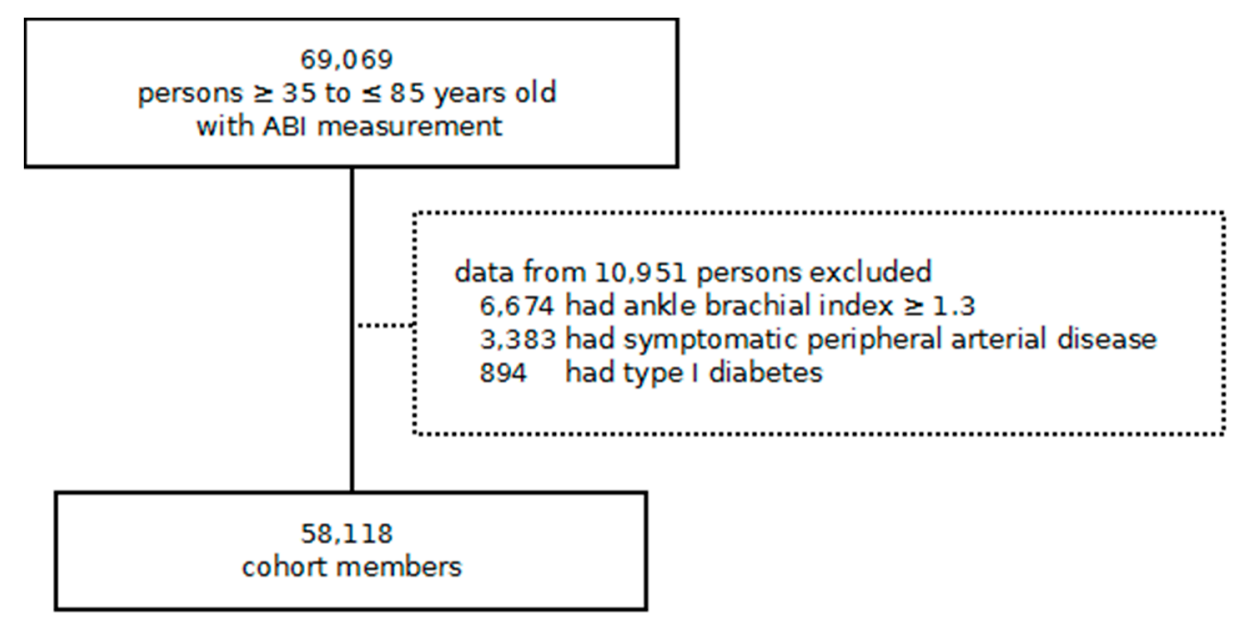

Figure 1. Study flowchart. ABI indicates ankle-brachial index.

We imputed the missing values of weight, height, systolic BP, pulse pressure, glucose, total cholesterol, HDL cholesterol, LDL cholesterol, and triglycerides. Appendix A Table A1 quantifies the missing variables and displays a comparison of the complete cases and imputed datasets for the whole study population. The maximum percentage of missing values was $32.8 \%$ for BMI. Although the participants' characteristics in both subsets were very similar, the subset of complete cases tended to be in slightly worse condition, i.e., higher percentage of patients with hypertension and being treated with antidiabetic drugs, agents acting on the renin-angiotensin system, statins, or with aspirin.

Mean age (SD) of the whole study population was 66.6 (10.7) years old, and 31,064 (53.4\%) were men. The groups with low ABI included a higher percentage of smokers, greater prevalence of chronic kidney disease and chronic obstructive pulmonary disease, and a slightly higher mean pulse pressure compared to the groups with normal ABI (Table 1). The groups with low ABI and no previous CVD had a higher percentage of persons taking aspirin and a greater prevalence of atrial fibrillation compared to the groups with normal ABI and no previous CVD. The groups with previous CVD had higher mean values of pulse pressure and a higher percentage of men, persons with hypertension, smokers, and patients receiving treatment with the considered medications, compared to the groups with no previous CVD. Persons in the groups with no previous CVD who had diabetes showed lower total and LDL cholesterol mean values. Finally, the groups with diabetes included a higher percentage of persons with hypertension, with chronic kidney disease, and being treated with the medications considered compared to the groups with no diabetes; this was observed especially in participants with additional previous CVD (Table 1). 
Table 1. Baseline characteristics of the study population according to diabetes, prior CVD, and ankle-brachial index.

\begin{tabular}{|c|c|c|c|c|c|c|c|c|}
\hline & \multicolumn{4}{|c|}{ No Diabetes } & \multicolumn{4}{|c|}{ Diabetes } \\
\hline & \multicolumn{2}{|c|}{ No CVD } & \multicolumn{2}{|c|}{ Prior CVD } & \multicolumn{2}{|c|}{ No CVD } & \multicolumn{2}{|c|}{ Prior CVD } \\
\hline & No LOW.ABI & LOW.ABI ${ }^{a}$ & No LOW.ABI & LOW.ABI & No LOW.ABI & LOW.ABI & No LOW.ABI & LOW.ABI \\
\hline$n(\%)$ & $11,850(20.4 \%)$ & $1880(3.2 \%)$ & $2064(3.6 \%)$ & $1027(1.8 \%)$ & $27,434(47.2 \%)$ & $5142(8.8 \%)$ & $6086(10.5 \%)$ & $2635(4.5 \%)$ \\
\hline Age, years & $64.6(11.4)$ & $66.3(11.9)$ & $69.7(9.8)$ & $69.8(10.0)$ & $65.8(10.5)$ & $67.9(10.4)$ & $69.9(9.1)$ & $70.7(9.1)$ \\
\hline Male, $n(\%)$ & $5353(45.2 \%)$ & $1068(56.8 \%)$ & $1350(65.4 \%)$ & $799(77.8 \%)$ & $13,853(50.5 \%)$ & $2819(54.8 \%)$ & $3978(65.4 \%)$ & $1844(70.0 \%)$ \\
\hline Smoker, $n(\%)$ & $2786(23.5 \%)$ & $711(37.8 \%)$ & $648(31.4 \%)$ & $525(51.1 \%)$ & $6172(22.5 \%)$ & $1458(28.4 \%)$ & $1762(29.0 \%)$ & $948(36.0 \%)$ \\
\hline Weight, kg & $76.3(14.4)$ & $77.2(15.4)$ & $77.1(13.1)$ & $76.0(13.4)$ & $79.0(14.8)$ & $78.9(14.8)$ & $79.1(13.9)$ & $78.1(13.8)$ \\
\hline Height, $\mathrm{cm}$ & $161.1(9.3)$ & $161.8(9.3)$ & $162.3(8.7)$ & $162.7(8.3)$ & $161.2(9.5)$ & $161.2(9.4)$ & $162.2(9.0)$ & $162.2(8.9)$ \\
\hline Body mass index, $\mathrm{kg} / \mathrm{m}^{2}$ & $29.4(4.7)$ & $29.4(5.0)$ & $29.3(4.3)$ & $28.7(4.2)$ & $30.4(5.0)$ & $30.4(5.1)$ & $30.1(4.5)$ & $29.7(4.5)$ \\
\hline Systolic BP, mmHg & $133.1(15.3)$ & $135.1(16.2)$ & $132.6(15.7)$ & $136.2(18.3)$ & $135.8(15.4)$ & $138.5(17.2)$ & $135.2(16.3)$ & $137.7(17.5)$ \\
\hline Diastolic BP, mmHg & $77.9(9.4)$ & $77.5(10.2)$ & $75.6(9.8)$ & $75.1(10.8)$ & $77.3(9.4)$ & $76.4(9.9)$ & $74.3(9.6)$ & $73.5(10.4)$ \\
\hline Pulse pressure, $\mathrm{mmHg}$ & $55.2(13.3)$ & $57.6(14.2)$ & $57.0(14.1)$ & $61.1(15.8)$ & $58.4(14.1)$ & $62.0(15.9)$ & $60.9(14.8)$ & $64.2(16.0)$ \\
\hline Total cholesterol, $\mathrm{mmol} / \mathrm{L}$ & $5.5(0.9)$ & $5.5(1.0)$ & $5.0(1.0)$ & $5.2(1.1)$ & $5.1(1.0)$ & $5.1(1.0)$ & $4.6(1.0)$ & $4.7(1.0)$ \\
\hline LDL cholesterol, mmol/L & $3.4(0.8)$ & $3.4(0.9)$ & $3.0(0.9)$ & $3.2(0.9)$ & $3.0(0.8)$ & $3.0(0.8)$ & $2.6(0.8)$ & $2.7(0.8)$ \\
\hline HDL cholesterol, $\mathrm{mmol} / \mathrm{L}$ & $1.5(0.5)$ & $1.4(0.5)$ & $1.4(0.4)$ & $1.4(0.5)$ & $1.4(0.4)$ & $1.3(0.4)$ & $1.3(0.4)$ & $1.2(0.4)$ \\
\hline Triglycerides, mmol/L & $1.4(0.9)$ & $1.5(0.9)$ & $1.5(0.9)$ & $1.6(0.9)$ & $1.7(1.1)$ & $1.8(1.2)$ & $1.7(1.0)$ & $1.8(1.3)$ \\
\hline Glucose, $\mathrm{mmol} / \mathrm{L}$ & $5.4(0.9)$ & $5.4(0.9)$ & $5.4(0.8)$ & $5.5(0.9)$ & $8.3(2.8)$ & $8.6(3.0)$ & $8.1(2.7)$ & $8.4(2.9)$ \\
\hline \multicolumn{9}{|l|}{ Comorbidities, $n$ (\%) } \\
\hline Hypertension & $6963(58.8 \%)$ & $1134(60.3 \%)$ & $1476(71.5 \%)$ & $743(72.3 \%)$ & $18,350(66.9 \%)$ & $3740(72.7 \%)$ & $4874(80.1 \%)$ & $2178(82.7 \%)$ \\
\hline Atrial fibrillation & $448(3.8 \%)$ & $109(5.8 \%)$ & $275(13.3 \%)$ & $135(13.1 \%)$ & $1218(4.4 \%)$ & $342(6.7 \%)$ & $772(12.7 \%)$ & $366(13.9 \%)$ \\
\hline Malignant neoplasm & $850(7.2 \%)$ & $163(8.7 \%)$ & $208(10.1 \%)$ & $115(11.2 \%)$ & $2173(7.9 \%)$ & $425(8.3 \%)$ & $618(10.2 \%)$ & $293(11.1 \%)$ \\
\hline Chronic kidney disease & $325(2.7 \%)$ & $77(4.1 \%)$ & $152(7.4 \%)$ & $96(9.3 \%)$ & $1069(3.9 \%)$ & $276(5.4 \%)$ & $600(9.9 \%)$ & $350(13.3 \%)$ \\
\hline COPD & $991(8.4 \%)$ & $288(15.3 \%)$ & $377(18.3 \%)$ & $268(26.1 \%)$ & $2328(8.5 \%)$ & $661(12.9 \%)$ & $978(16.1 \%)$ & $551(20.9 \%)$ \\
\hline \multicolumn{9}{|l|}{ Medication, $n(\%)$} \\
\hline Antidiabetic therapy & $0(0.0 \%)$ & $0(0.0 \%)$ & $0(0.0 \%)$ & $0(0.0 \%)$ & $21,388(78.0 \%)$ & $4193(81.5 \%)$ & $5014(82.4 \%)$ & $2251(85.4 \%)$ \\
\hline Diuretics & $2565(21.6 \%)$ & $483(25.7 \%)$ & $606(29.4 \%)$ & $303(29.5 \%)$ & $6369(23.2 \%)$ & $1414(27.5 \%)$ & $2102(34.5 \%)$ & $998(37.9 \%)$ \\
\hline Beta-blockers & $1234(10.4 \%)$ & $232(12.3 \%)$ & $651(31.5 \%)$ & $280(27.3 \%)$ & $3382(12.3 \%)$ & $701(13.6 \%)$ & $2557(42.0 \%)$ & $977(37.1 \%)$ \\
\hline Calcium channel blockers & $1258(10.6 \%)$ & $243(12.9 \%)$ & $506(24.5 \%)$ & $253(24.6 \%)$ & $4516(16.5 \%)$ & $1009(19.6 \%)$ & $2024(33.3 \%)$ & $912(34.6 \%)$ \\
\hline Agents acting on the renin angiotensin system & $4719(39.8 \%)$ & $844(44.9 \%)$ & $1144(55.4 \%)$ & $562(54.7 \%)$ & $15,536(56.6 \%)$ & $3281(63.8 \%)$ & $4311(70.8 \%)$ & $1941(73.7 \%)$ \\
\hline Other antihypertensives & $321(2.7 \%)$ & $62(3.3 \%)$ & $87(4.2 \%)$ & $46(4.5 \%)$ & $1257(4.6 \%)$ & $291(5.7 \%)$ & $450(7.4 \%)$ & $207(7.9 \%)$ \\
\hline Statins & $2726(23.0 \%)$ & $503(26.8 \%)$ & $1154(55.9 \%)$ & $538(52.4 \%)$ & $12,207(44.5 \%)$ & $2445(47.5 \%)$ & $4339(71.3 \%)$ & $1837(69.7 \%)$ \\
\hline Other lipid lowering agents & $345(2.9 \%)$ & $72(3.8 \%)$ & $118(5.7 \%)$ & $63(6.1 \%)$ & $1875(6.8 \%)$ & $341(6.6 \%)$ & $686(11.3 \%)$ & 299 (11.3\%) \\
\hline Aspirin & $1013(8.5 \%)$ & $326(17.3 \%)$ & $1137(55.1 \%)$ & $552(53.7 \%)$ & $7366(26.8 \%)$ & $1754(34.1 \%)$ & $4012(65.9 \%)$ & $1692(64.2 \%)$ \\
\hline Follow-up, years, (1st quartile, 3rd quartile) & $6.2(4.8,7.9)$ & $5.7(4.6,7.4)$ & $5.8(4.6,7.5)$ & $5.6(4.5,7.2)$ & $6.1(4.8,7.5)$ & $5.8(4.7,7.5)$ & $5.6(4.6,7.2)$ & $5.3(4.2,7.1)$ \\
\hline Lost to follow-up, $n(\%)^{b}$ & $194(1.6 \%)$ & $30(1.6 \%)$ & $33(1.6 \%)$ & $16(1.6 \%)$ & $419(1.5 \%)$ & $92(1.8 \%)$ & $89(1.5 \%)$ & $41(1.6 \%)$ \\
\hline
\end{tabular}

${ }^{\mathrm{a}} \mathrm{ABI}<0.9{ }^{\mathrm{b}}$ With respect to the number of participants in that group. Values are mean (standard deviation), unless otherwise specified. ABI indicates ankle-brachial index; BP, blood

pressure; CVD, cardiovascular disease; COPD, chronic obstructive pulmonary disease; HDL, high density lipoprotein; LDL, low density lipoprotein; $n$, number of persons. 
Overall, 8382 participants died during the follow-up period, an all-cause mortality incidence of 23.8 (95\% CI 23.3, 24.3) per 1000 person-years; 2154 had an AMI, an incidence rate of 6.2 (6.0, 6.5) per 1000 person-years; and 3922 had IS, an incidence rate of $11.5(11.1,11.8)$ per 1000 person-years. The incidences of the considered outcomes by categories of exposure were highest in the group with diabetes, prior CVD, and low ABI values, and lowest in the reference group (no diabetes, no prior CVD, and normal ABI values) (Table 2).

Table 2. Raw incidences of all-cause mortality, acute myocardial infarction, and ischemic stroke by population groups.

\begin{tabular}{|c|c|c|c|c|c|c|c|c|}
\hline \multicolumn{3}{|c|}{ Group } & \multicolumn{2}{|c|}{ All-Cause Mortality } & \multicolumn{2}{|c|}{$\begin{array}{l}\text { Acute Myocardial } \\
\text { Infarction }\end{array}$} & \multicolumn{2}{|c|}{ Ischemic Stroke } \\
\hline Diabetes & CVD & Low ABI ${ }^{a}$ & Events $^{b}$ & $\begin{array}{c}\text { Incidence Rate }^{c} \\
(95 \% \text { CI })\end{array}$ & Events & $\begin{array}{c}\text { Incidence } \\
\text { Rate }(95 \% \text { CI) }\end{array}$ & Events & $\begin{array}{c}\text { Incidence } \\
\text { Rate }(95 \% \text { CI })\end{array}$ \\
\hline Yes & Yes & Yes & 873 & $60.8(56.9,65.0)$ & 290 & $21.4(19.0,24.0)$ & 431 & $32.7(29.8,36.0)$ \\
\hline Yes & Yes & No & 1401 & $40.2(38.1,42.4)$ & 495 & $14.8(13.6,16.2)$ & 834 & $25.6(23.9,27.4)$ \\
\hline Yes & No & Yes & 965 & $31.3(29.4,33.4)$ & 208 & $6.9(6.0,7.9)$ & 410 & $13.8(12.5,15.2)$ \\
\hline No & No & Yes & 281 & $25.4(22.6,28.5)$ & 62 & $5.7(4.4,7.3)$ & 104 & $9.7(8.0,11.7)$ \\
\hline Yes & No & No & 3146 & $18.7(18.0,19.3)$ & 728 & $4.4(4.1,4.7)$ & 1402 & $8.5(8.1,9.0)$ \\
\hline No & No & No & 1058 & $14.1(13.3,15.0)$ & 191 & $2.6(2.2,3.0)$ & 424 & $5.7(5.2,6.3)$ \\
\hline
\end{tabular}

The risk of all-cause mortality, AMI, and IS was compared between categories of exposure using the group with no diabetes, no previous CVD, and normal ABI as reference. Figure 2 shows the exposure groups by increasing adjusted HR for all-cause mortality, AMI, and IS. The risk for all the considered outcomes was highest in the group with diabetes, previous CVD, and low ABI. Low ABI alone showed an increase in all-cause mortality risk compared to the reference group, with a hazard ratio (HR) of $1.42(1.25,1.63)$, similar to the group with diabetes alone, HR $1.35(1.26,1.45)$, and slightly lower than in the group with previous CVD alone, HR $1.50(1.34,1.69)$. This latter group had lower all-cause mortality risk than participants with low ABI and diabetes, who had a HR of $1.84(1.68,2.01)$, and both confidence intervals nearly overlapped; the group with previous CVD alone and the group with low ABI and diabetes had similar values for AMI and IS. The trends for mortality in the rest of the groups were similar to AMI and IS. Tables A2 and A3 detail the unadjusted and adjusted HRs (95\% CI), respectively, for all the categories and outcomes. Appendix A Table A4 shows the HRs of the adjustment variables for each outcome.

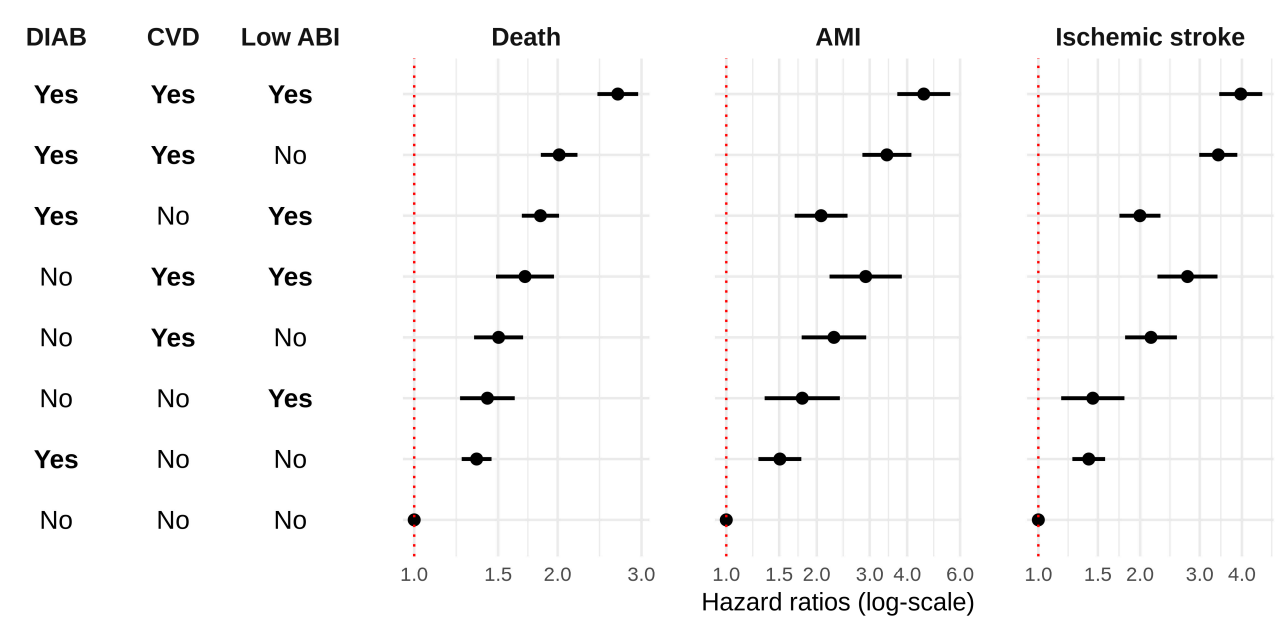

Figure 2. Hazard ratios and 95\% confidence intervals for all-cause mortality, acute myocardial infarction, and ischemic stroke by groups of exposure. ABI indicates ankle-brachial index; AMI, acute myocardial infarction; CVD previous cardiovascular disease; DIAB, diabetes. 
Sensitivity analyses restricted to the complete-cases dataset gave similar results (Tables A5-A7). Appendix A Table A5 presents data from the complete-cases dataset by population groups. As in the overall population, the subset of complete cases tended to be in slightly worse condition, but the group distribution was similar to the imputed dataset. Appendix A Table A6 presents the raw incidences in the subset of complete cases, which had a similar pattern to the imputed dataset; given the difference in sample sizes, the confidence intervals were slightly wider in the complete-cases subset than in the imputed dataset. Appendix A Table A7 shows the adjusted HRs for the complete- cases subset of population. The HRs were slightly higher for all-cause mortality and slightly lower for AMI and IS in the subset of complete cases compared to the imputed data. We also performed sensitivity analyses considering persons under and over 75 years of age, and forcing chronic kidney disease in the models-since it is a strong risk factor for AMI and stroke-which presented comparable results.

\section{Discussion}

We found that the presence of low ABI in asymptomatic persons was associated with increased all-cause mortality, AMI, and IS risk in all the studied subgroups, aside from the presence of diabetes or previous CVD. This increase was observed even in participants at highest risk (with both diabetes and previous (VD). At the other end of the risk array, persons with ABI alone presented an incidence of all the considered outcomes similar to persons with diabetes alone; this incidence was lower than in persons with previous CVD alone. Of note, participants with low ABI plus diabetes showed an increase in mortality, AMI, and IS risk similar to those with previous CVD.

Previous studies have evidenced the relation of low ABI with mortality or cardiovascular outcomes worldwide. In Central Africa, HR estimates for low ABI $(\leq 0.9)$ were 1.86 for mortality in a population aged $\geq 65$ years, $10 \%$ of whom had diabetes and $7 \%$ whom had a history of myocardial infarction [32]. In Japan, HR estimates for abnormal ABI ( $<0.9$ or $>1.4$ ) were 2.01 for major adverse cardiovascular events in a population with end-stage kidney disease, $38 \%$ of whom had diabetes and $28 \%$ whom had prior coronary revascularization [33]. In France, a HR for total mortality of 1.46 was reported in a population prior to coronary artery bypass grafting [34]. Comparison between studies is difficult, not only because of the differences in the design, but also in the characteristics of the populations.

The increase in all-cause mortality, AMI, and IS risk conferred by low ABI in asymptomatic participants with previous CVD and/or diabetes is compatible with low ABI being a surrogate of vascular damage in the context of polyvascular disease; indeed, low ABI has been reported to be useful in identifying this condition $[35,36]$. In addition to corroborating these findings, our results quantify the risk increase contributed by polyvascular damage, and are in line with previous recommendations to use $\mathrm{ABI}$ for the detection of asymptomatic PAD in persons with previous CVD and diabetes, both in isolation or when coexistent [37].

The damage associated with low ABI would be of interest not only in the context of polyvascular disease but also in persons with low $\mathrm{ABI}$ alone, in whom we found an all-cause mortality risk as high as in persons with diabetes. To date, evidence to recommend screening with ABI in asymptomatic persons has been deemed insufficient [38], even though some studies evidenced the benefit of screening of asymptomatic population at high risk which, although modest, should be taken into consideration $[39,40]$. Our results would support the need for this screening, although further studies specifically designed for this purpose would be of high interest. Even more, risk functions have been developed to help optimize the selection of candidates for screening of asymptomatic individuals [41]. Given the serious consequences of PAD, its early diagnosis in asymptomatic stages is crucial in terms of cardiovascular risk and to prevent its progression in the form of foot ulceration, gangrene, and eventual amputation of the affected part of the extremity [42].

The comparison of the group with previous CVD and the group with diabetes and additional low ABI merits special discussion. In several reports [43-46], patients with diabetes were considered as comparable to those with previous CVD, although others have argued against it $[47,48]$. This controversy was resolved with a tendency to ascribe higher risk to patients with previous CVD; 
consequently, recommendations and treatments for cardiovascular prevention were not as aggressive in patients with diabetes and no previous CVD [47]. However, some studies tried to reconcile these two positions on risk among patients with diabetes. Previous CVD conferred a risk similar to having diabetes in patients who required glucose-lowering medication [43], used insulin or had albuminuria [49], or if they had a longer duration of diabetes, i.e., 10-15 years [50,51]. Our study adds low ABI values to these findings. Further studies that examined the impact of variations of ABI over time would be of interest as to provide additional prognosis information.

The present analysis was performed with a database originated from clinical records, a 'real world' assessment [9] of all-cause mortality, AMI, and IS, based on a high number of participants; this provided sufficient power to stratify the population into groups of exposure that could be directly analyzed and compared. Working with SIDIAPQ also provided a high absolute number of outcomes and a long follow-up period. The study population should be taken into consideration when extrapolating our results. It was a population with risk factors for atherosclerotic disease (the mean age was 66.6 years, where $67.9 \%$ of participants had hypertension, $25.8 \%$ were smokers or had a history of smoking, $71.1 \%$ had diabetes, and $20.3 \%$ had previous CVD), to whom an ABI measurement would be recommended according to the prevention guidelines [4,52-55].

Our findings should be interpreted in light of some limitations. First, we did not describe and analyze hemoglobin A1c levels or the time since previous CVD because the study design required the use of the same variables for all patients in order to directly compare the groups and the risk of the outcomes. Some groups included participants with no diabetes or previous CVD and, thus, the amount of missing values for hemoglobin A1c would have been unacceptable; in addition, some participants did not have data regarding time since previous CVD. Second, potential residual confounding can never be totally dismissed, even though we adjusted for important cardiovascular risk factors. Third, poor quality of the data could generate misclassification in studies with electronic medical records, but the presence of cardiovascular risk factors and outcomes has been previously validated in SIDIAP [15]. Fourth, the presence of missing data can influence the results but, in this study, the maximum percentage of missing values for a variable was $32.8 \%$, and the characteristics of the complete-case analyses did not differ from imputed data. Finally, SIDIAPQ does not contain records on cause of death and, thus, we could not assess cardiovascular death specifically, but our results indicate that it could be partially explained, in most of the studied subgroups, by the cardiovascular outcomes considered.

In conclusion, low ABI was associated with increased all-cause mortality, AMI, and IS risk at rates similar to diabetes but less than previous CVD. The risk of AMI or IS in persons with diabetes was similar to that in persons with previous CVD, provided low ABI was also present. These findings will contribute to improve awareness on the risk associated with low $\mathrm{ABI}$ in asymptomatic patients, and support the need for further studies to elucidate who should be screened in order to optimize CVD prevention.

Author Contributions: Conceptualization, L.A.-C., M.G.-G. and R.R.; Data curation, M.C.-C., J.B. and M.E.-B.; Formal analysis, M.C.-C. and J.B.; Funding acquisition, M.G.-G., R.M.-L. and R.R.; Investigation, L.A.-C., M.G.-G., A.P., R.M.-L., M.E.-B. and D.P.; Methodology, L.A.-C., M.G.-G., M.C.-C., A.P., R.M.-L., L.C. and R.R.; Project administration, L.A.-C. and R.R.; Resources, L.A.-C., M.G.-G., R.M.-L. and R.R.; Software, M.C.-C., J.B. and M.E.-B.; Supervision, L.A.-C., M.G.-G. and R.R.; Validation, L.A.-C., M.C.-C., J.B., A.P., D.P., L.C. and R.R.; Visualization, L.A.-C., M.C.-C., A.P., D.P., L.C. and R.R.; Writing, original draft, L.A.-C., A.P.; Writing, review \& editing, M.G.-G., M.C.-C., J.B., A.P., R.M.-L., M.E.-B., D.P., L.C. and R.R.

Funding: This project was supported by clinical research grants from Spain's Health Ministry (ED10-83, EC10-84) and Science and Innovation Ministry (Carlos III Health Institute), cofinanced with European Union ERDF funds (Network for Prevention and Health Promotion in Primary Care, RedIAPP RD16/0007), and the Agency for Management of University and Research Grants (2017 SGR 1146). The funding sources were not involved in study design; collection, analysis, and interpretation of data; report writing; or the decision to submit the article for publication. The authors take sole responsibility for the integrity of the data and the accuracy of the analysis.

Acknowledgments: We appreciate the English revision of the manuscript by Elaine Lilly.

Conflicts of Interest: The authors declare no conflict of interest. 


\section{Appendix A}

\section{Appendix A.1. Methods}

Validation of the Imputation Process [27,29]

In the multiple imputation stage, we checked for normality, correlations, and collinearity between variables with missing data and variables that could be included in the multiple imputation. Next, we identified variables related to missing values and/or to missing variables.

The imputation models included the following variables: age, sex, ankle-brachial index (ABI), weight, height, natural logarithm (ln) of systolic blood pressure, ln (pulse pressure), ln (glucose), ln (total cholesterol), ln (high density lipoprotein cholesterol), ln (low density lipoprotein cholesterol), ln (triglycerides), smoking status, hypertension, hypercholesterolemia, arthritis, asthma, chronic obstructive pulmonary disease, atrial fibrillation, malignant neoplasms, chronic kidney disease, hypothyroidism, previous history of acute myocardial infarction (AMI), angina pectoris, transient ischemic attack, stroke, and medications (antidiabetic drugs, diuretics, beta blocking agents, calcium-channel blockers, agents acting on the renin-angiotensin system, other antihypertensive agents, corticosteroids for systemic use, psycholeptics, psychoanaleptics, statins, other lipid-lowering drugs, and aspirin. We also included the censoring indicator and the Nelson-Aalen estimate of the cumulative hazard function for the time to cardiovascular disease [28].

The $\ln$ transformation was applied to some variables, as indicated in the list above, to improve the normality of the distribution and to avoid the unlikely possibility of imputing any negative numbers. After imputation, variables were converted back to their original scale.

Appendix A Table A1 shows the number (percentage) of missing values for each variable of interest and the baseline characteristics of the whole imputed population, and of the subset with complete cases.

Table A1. Missing counts and comparison of baseline characteristics of the whole study population for the imputed and complete-cases datasets.

\begin{tabular}{|c|c|c|c|}
\hline Variable & Missing Counts ${ }^{a}$ & $\begin{array}{c}\text { Imputed } \\
n=58,118\end{array}$ & $\begin{array}{c}\text { Complete Cases } \\
n=28,206\end{array}$ \\
\hline Age, years & - & $66.6(10.7)$ & $67.3(10.1)$ \\
\hline Male, $n(\%)$ & - & $31,064(53.4 \%)$ & $15,012(53.2 \%)$ \\
\hline Smoker, $n(\%)$ & - & $15,010(25.8 \%)$ & $7086(25.1 \%)$ \\
\hline Weight, kg & $14,604(25.1 \%)$ & $78.3(14.6)$ & $78.2(13.9)$ \\
\hline Height, $\mathrm{cm}$ & $18,921(32.6 \%)$ & $161.4(9.3)$ & $161.1(9.2)$ \\
\hline Body mass index, $\mathrm{kg} / \mathrm{m}^{2}$ & $19,073(32.8 \%)$ & $30.0(4.8)$ & $30.1(4.7)$ \\
\hline Systolic BP, mmHg & $7652(13.2 \%)$ & $135.4(15.9)$ & $135.7(15.5)$ \\
\hline Diastolic BP, mmHg & $7652(13.2 \%)$ & $76.8(9.7)$ & $76.5(9.5)$ \\
\hline Pulse pressure, $\mathrm{mmHg}$ & $7652(13.2 \%)$ & $58.6(14.5)$ & $59.2(14.3)$ \\
\hline Total cholesterol, mmol/L & $14,366(24.7 \%)$ & $5.1(1.0)$ & $5.1(1.0)$ \\
\hline LDL cholesterol, mmol/L & $18,625(32.0 \%)$ & $3.0(0.9)$ & $3.0(0.8)$ \\
\hline HDL cholesterol, mmol/L & $18,179(31.3 \%)$ & $1.4(0.4)$ & $1.3(0.4)$ \\
\hline Triglycerides, mmol/L & $16,954(29.2 \%)$ & $1.7(1.1)$ & $1.7(1.0)$ \\
\hline Glucose, $\mathrm{mmol} / \mathrm{L}$ & $13,746(23.7 \%)$ & $7.5(2.8)$ & $7.7(2.7)$ \\
\hline \multicolumn{4}{|l|}{ Comorbidities, $n(\%)$} \\
\hline Hypertension & - & $39,458(67.9 \%)$ & $20,624(73.1 \%)$ \\
\hline Atrial fibrillation & - & $3665(6.3 \%)$ & $1818(6.4 \%)$ \\
\hline Malignant neoplasm & - & $4845(8.3 \%)$ & $2292(8.1 \%)$ \\
\hline Chronic kidney disease & - & $2945(5.1 \%)$ & $1502(5.3 \%)$ \\
\hline COPD & - & $6442(11.1 \%)$ & $3169(11.2 \%)$ \\
\hline Acute myocardial infarction & & $6922(11.91 \%)$ & $3277(11.62 \%)$ \\
\hline Angina & & $2680(4.61 \%)$ & $1395(4.95 \%)$ \\
\hline Stroke & & $2913(5.01 \%)$ & $1475(5.23 \%)$ \\
\hline Transient ischemic attack & & $1640(2.82 \%)$ & $831(2.95 \%)$ \\
\hline
\end{tabular}


Table A1. Cont.

\begin{tabular}{|c|c|c|c|c|c|}
\hline \multicolumn{3}{|c|}{ Variable } & Missing Counts ${ }^{a}$ & $\begin{array}{c}\text { Imputed } \\
n=58,118\end{array}$ & $\begin{array}{c}\text { Complete Cases } \\
n=28,206\end{array}$ \\
\hline \multicolumn{6}{|c|}{ Medication, $n(\%)$} \\
\hline \multicolumn{3}{|c|}{ Antidiabetic therapy } & - & $32,846(56.5 \%)$ & $18,480(65.5 \%)$ \\
\hline \multicolumn{3}{|c|}{ Diuretics } & - & $14,840(25.5 \%)$ & $7627(27.0 \%)$ \\
\hline \multicolumn{3}{|c|}{ Beta-blockers } & - & $10,014(17.2 \%)$ & $5191(18.4 \%)$ \\
\hline \multicolumn{3}{|c|}{ Calcium channel blockers } & - & $10,721(18.4 \%)$ & $5787(20.5 \%)$ \\
\hline \multicolumn{3}{|c|}{ Agents acting on the renin-angiotensin syste } & $\mathrm{m}$ & $32,338(55.6 \%)$ & $17,418(61.8 \%)$ \\
\hline \multicolumn{3}{|c|}{ Other antihypertensives } & - & $2721(4.7 \%)$ & $1378(4.9 \%)$ \\
\hline \multicolumn{3}{|c|}{ Statins } & - & $25,749(44.3 \%)$ & $14,419(51.1 \%)$ \\
\hline \multicolumn{3}{|c|}{ Other lipid-lowering agents } & - & $3799(6.5 \%)$ & $1995(7.1 \%)$ \\
\hline \multicolumn{3}{|c|}{ Aspirin } & - & $17,852(30.7 \%)$ & $9636(34.2 \%)$ \\
\hline \multicolumn{3}{|c|}{ Follow-up, years (1st quartile, 3rd quartile) } & - & $5.9(4.7,7.6)$ & $5.8(4.7,7.2)$ \\
\hline \multicolumn{3}{|c|}{ Lost to follow-up, $n(\%)$} & - & $914(1.6 \%)$ & $421(1.5 \%)$ \\
\hline \multicolumn{6}{|c|}{$\begin{array}{l}\text { Abbreviations: BP, blood pressure; COPD, chronic obstructive pulmonary disease; HDL, high density lipoprotein; } \\
\text { LDL, low density lipoprotein; } n \text {, number of persons; SD, standard deviation. Values are mean (standard deviation), } \\
\text { unless otherwise specified. }{ }^{a} n(\%) \text {. }\end{array}$} \\
\hline \multicolumn{6}{|c|}{$\begin{array}{l}\text { Table A2. Unadjusted hazard ratios ( } 95 \% \text { confidence intervals) for all-cause mortality, acute myocardial } \\
\text { infarction, and ischemic stroke, by groups. }\end{array}$} \\
\hline \multicolumn{3}{|c|}{ Group } & \multicolumn{3}{|c|}{ Hazard Ratio (95\% Confidence Interval) } \\
\hline Diabetes & CVD & Low ABI & All-Cause Mortality & AMI & Ischemic Stroke \\
\hline Yes & Yes & Yes & $2.74(2.32,3.24)$ & $4.51(3.26,6.23)$ & $3.89(3.09,4.89)$ \\
\hline Yes & Yes & No & $2.08(1.78,2.42)$ & $3.28(2.41,4.46)$ & $3.38(2.74,4.17)$ \\
\hline Yes & No & Yes & $2.11(1.81,2.47)$ & $1.83(1.31,2.54)$ & $1.87(1.49,2.34)$ \\
\hline No & Yes & Yes & $1.58(1.21,2.07)$ & $1.96(1.14,3.36)$ & $2.44(1.69,3.53)$ \\
\hline No & Yes & No & $1.66(1.34,2.07)$ & $1.98(1.27,3.10)$ & $1.85(1.35,2.54)$ \\
\hline No & No & Yes & $1.54(1.21,1.97)$ & $1.76(1.08,2.88)$ & $1.32(0.90,1.92)$ \\
\hline Yes & No & No & $1.52(1.33,1.74)$ & $1.47(1.11,1.94)$ & $1.44(1.19,1.74)$ \\
\hline No & No & No & Reference & Reference & Reference \\
\hline
\end{tabular}

Abbreviations: ABI, ankle-brachial index; AMI, acute myocardial infarction; CVD, cardiovascular disease.

Table A3. Adjusted hazard ratios (95\% confidence intervals) for all-cause mortality, acute myocardial infarction, and ischemic stroke, by groups.

\begin{tabular}{cccccc}
\hline & Group & \multicolumn{3}{c}{ Hazard Ratio (95\% Confidence Interval) } \\
\hline Diabetes & CVD & Low ABI & All-Cause Mortality & AMI & Ischemic Stroke \\
\hline Yes & Yes & Yes & $2.68(2.42,2.95)$ & $4.54(3.71,5.56)$ & $3.97(3.43,4.59)$ \\
Yes & Yes & No & $2.01(1.84,2.20)$ & $3.42(2.84,4.13)$ & $3.41(2.99,3.88)$ \\
Yes & No & Yes & $1.84(1.68,2.01)$ & $2.07(1.69,2.53)$ & $2.00(1.74,2.30)$ \\
No & Yes & Yes & $1.71(1.49,1.97)$ & $2.91(2.21,3.84)$ & $2.76(2.25,3.39)$ \\
No & Yes & No & $1.50(1.34,1.69)$ & $2.28(1.78,2.92)$ & $2.15(1.81,2.57)$ \\
No & No & Yes & $1.42(1.25,1.63)$ & $1.79(1.34,2.39)$ & $1.45(1.17,1.80)$ \\
Yes & No & No & $1.35(1.26,1.45)$ & $1.51(1.28,1.78)$ & $1.41(1.26,1.58)$ \\
No & No & No & Reference & Reference & Reference \\
\hline
\end{tabular}

Abbreviations: ABI, ankle-brachial index; AMI, acute myocardial infarction; CVD, cardiovascular disease. 
Table A4. Variables of adjustment in the Cox proportional hazard models for each outcome.

\begin{tabular}{|c|c|c|c|}
\hline \multirow{2}{*}{ Variable of Adjustment } & \multicolumn{3}{|c|}{ Outcome } \\
\hline & Mortality & AMI & Stroke \\
\hline Age & $\sqrt{ }$ & $\sqrt{ }$ & $\sqrt{ }$ \\
\hline $\mathrm{Age}^{2}$ & $\sqrt{ }$ & $\sqrt{ }$ & $\sqrt{ }$ \\
\hline Male & $\sqrt{ }$ & $\sqrt{ }$ & $\sqrt{ }$ \\
\hline Smoker & $\sqrt{ }$ & $\sqrt{ }$ & $\sqrt{ }$ \\
\hline BMI & $\sqrt{ }$ & $\sqrt{ }$ & $\sqrt{ }$ \\
\hline Pulse pressure & $\sqrt{ }$ & $\sqrt{ }$ & $\sqrt{ }$ \\
\hline LDL cholesterol & $\sqrt{ }$ & $\sqrt{ }$ & \\
\hline HDL cholesterol & $\sqrt{ }$ & $\sqrt{ }$ & $\sqrt{ }$ \\
\hline Triglycerides & & $\sqrt{ }$ & $\sqrt{ }$ \\
\hline \multicolumn{4}{|l|}{ Comorbidities } \\
\hline Hypertension & & & $\sqrt{ }$ \\
\hline Atrial fibrillation & $\sqrt{ }$ & $\sqrt{ }$ & $\sqrt{ }$ \\
\hline Malignant neoplasm & $\sqrt{ }$ & & \\
\hline Chronic kidney disease & $\sqrt{ }$ & & \\
\hline COPD & $\sqrt{ }$ & $\sqrt{ }$ & $\sqrt{ }$ \\
\hline \multicolumn{4}{|l|}{ Medications } \\
\hline Diuretics & $\sqrt{ }$ & $\sqrt{ }$ & $\sqrt{ }$ \\
\hline Beta-blockers & $\sqrt{ }$ & $\sqrt{ }$ & $\sqrt{ }$ \\
\hline Calcium channel blockers & $\sqrt{ }$ & $\sqrt{ }$ & $\sqrt{ }$ \\
\hline Agents acting on the renin angiotensin system & $\sqrt{ }$ & $\sqrt{ }$ & $\sqrt{ }$ \\
\hline Statins & $\sqrt{ }$ & $\sqrt{ }$ & $\sqrt{ }$ \\
\hline Other lipid lowering agents & & $\sqrt{ }$ & \\
\hline Aspirin & $\sqrt{ }$ & $\sqrt{ }$ & $\sqrt{ }$ \\
\hline
\end{tabular}

Abbreviations: AMI, acute myocardial infarction; BMI, body mass index; COPD, chronic obstructive pulmonary disease; HDL, high density lipoprotein; LDL, low density lipoprotein. 
Table A5. Baseline characteristics of the study population according to diabetes, prior CVD, and ankle-brachial index. Complete cases.

\begin{tabular}{|c|c|c|c|c|c|c|c|c|}
\hline & \multicolumn{4}{|c|}{ No Diabetes } & \multicolumn{4}{|c|}{ Diabetes } \\
\hline & \multicolumn{2}{|c|}{ No CVD } & \multicolumn{2}{|c|}{ Prior CVD } & \multicolumn{2}{|c|}{ No CVD } & \multicolumn{2}{|c|}{ Prior CVD } \\
\hline & No LOW.ABI & LOW.ABI $^{a}$ & No LOW.ABI & LOW.ABI & No LOW.ABI & LOW.ABI & No LOW.ABI & LOW.ABI \\
\hline$n(\%)$ & $3704(13.1 \%)$ & $645(2.3 \%)$ & $736(2.6 \%)$ & $337(1.2 \%)$ & $15,373(54.5 \%)$ & $2696(9.6 \%)$ & $3304(11.7 \%)$ & $1411(5.0 \%)$ \\
\hline Age, years & $66.8(10.3)$ & $68.4(10.5)$ & $70.4(8.7)$ & $71.1(9.5)$ & $66.1(10.2)$ & $68.2(10.0)$ & $70.0(8.9)$ & $70.9(8.8)$ \\
\hline Male, $n(\%)$ & $1650(44.5 \%)$ & $383(59.4 \%)$ & $476(64.7 \%)$ & $256(76.0 \%)$ & $7621(49.6 \%)$ & $1500(55.6 \%)$ & $2136(64.6 \%)$ & $990(70.2 \%)$ \\
\hline Smoker, $n(\%)$ & $798(21.5 \%)$ & $220(34.1 \%)$ & $216(29.3 \%)$ & $163(48.4 \%)$ & $3417(22.2 \%)$ & $780(28.9 \%)$ & $971(29.4 \%)$ & $521(36.9 \%)$ \\
\hline Weight, kg & $76.3(13.7)$ & $77.4(14.7)$ & $76.6(12.4)$ & $75.2(11.7)$ & $78.6(14.1)$ & $78.8(14.1)$ & $78.8(13.4)$ & $78.0(13.6)$ \\
\hline Height, $\mathrm{cm}$ & $160.4(9.2)$ & $161.5(9.1)$ & $161.9(8.5)$ & $162.0(8.0)$ & $160.9(9.4)$ & $161.2(9.2)$ & $162.0(9.0)$ & $162.0(8.9)$ \\
\hline Body mass index, $\mathrm{kg} / \mathrm{m}^{2}$ & $29.6(4.5)$ & $29.6(4.8)$ & $29.2(4.0)$ & $28.6(3.9)$ & $30.3(4.8)$ & $30.4(5.0)$ & $30.0(4.4)$ & $29.7(4.5)$ \\
\hline Hypertension, $n(\%)$ & $2780(75.1 \%)$ & $499(77.4 \%)$ & $593(80.6 \%)$ & $279(82.8 \%)$ & $10,579(68.8 \%)$ & $2015(74.7 \%)$ & $2694(81.5 \%)$ & $1185(84.0 \%)$ \\
\hline Systolic BP, mmHg & $134.4(14.9)$ & $136.2(16.3)$ & $133.9(15.1)$ & $135.8(17.5)$ & $135.5(15.1)$ & $138.4(16.9)$ & $135.2(15.7)$ & $137.3(17.2)$ \\
\hline Diastolic $\mathrm{BP}, \mathrm{mmHg}$ & $77.7(9.5)$ & $76.7(9.9)$ & $75.8(9.9)$ & $74.0(10.0)$ & $77.1(9.3)$ & $76.2(9.7)$ & $74.1(9.5)$ & $73.3(10.2)$ \\
\hline Pulse pressure, $\mathrm{mmHg}$ & $56.7(13.3)$ & $59.5(14.7)$ & $58.1(14.1)$ & $61.8(15.2)$ & $58.4(13.8)$ & $62.2(15.7)$ & $61.0(14.6)$ & $64.0(16.1)$ \\
\hline Total cholesterol, $\mathrm{mmol} / \mathrm{L}$ & $5.5(0.9)$ & $5.5(1.0)$ & $5.0(1.0)$ & $5.1(1.0)$ & $5.1(0.9)$ & $5.1(1.0)$ & $4.6(0.9)$ & $4.7(1.0)$ \\
\hline LDL cholesterol, $\mathrm{mmol} / \mathrm{L}$ & $3.4(0.8)$ & $3.4(0.9)$ & $2.9(0.8)$ & $3.1(0.9)$ & $2.9(0.8)$ & $3.0(0.8)$ & $2.6(0.8)$ & $2.7(0.8)$ \\
\hline HDL cholesterol, $\mathrm{mmol} / \mathrm{L}$ & $1.5(0.4)$ & $1.4(0.4)$ & $1.4(0.4)$ & $1.3(0.3)$ & $1.3(0.3)$ & $1.3(0.3)$ & $1.3(0.3)$ & $1.2(0.3)$ \\
\hline Triglycerides, mmol/L & $1.4(0.8)$ & $1.5(0.8)$ & $1.5(0.8)$ & $1.5(0.8)$ & $1.7(1.0)$ & $1.7(1.0)$ & $1.7(0.9)$ & $1.7(1.1)$ \\
\hline Glucose, $\mathrm{mmol} / \mathrm{L}$ & $5.4(0.9)$ & $5.5(0.9)$ & $5.4(0.7)$ & $5.4(0.7)$ & $8.2(2.7)$ & $8.4(2.9)$ & $8.0(2.6)$ & $8.4(2.9)$ \\
\hline \multicolumn{9}{|l|}{ Comorbidities, $n(\%)$} \\
\hline Atrial fibrillation & $170(4.6 \%)$ & $45(7.0 \%)$ & $102(13.9 \%)$ & $43(12.8 \%)$ & $684(4.4 \%)$ & $163(6.0 \%)$ & $407(12.3 \%)$ & $204(14.5 \%)$ \\
\hline Malignant neoplasm & $269(7.3 \%)$ & $48(7.4 \%)$ & $69(9.4 \%)$ & 39 (11.6\%) & $1180(7.7 \%)$ & $206(7.6 \%)$ & $330(10.0 \%)$ & $151(10.7 \%)$ \\
\hline Chronic kidney disease & $144(3.9 \%)$ & $31(4.8 \%)$ & $60(8.2 \%)$ & $41(12.2 \%)$ & $598(3.9 \%)$ & $142(5.3 \%)$ & $312(9.4 \%)$ & $174(12.3 \%)$ \\
\hline COPD & $354(9.6 \%)$ & $103(16.0 \%)$ & $139(18.9 \%)$ & $109(32.3 \%)$ & $1295(8.4 \%)$ & $338(12.5 \%)$ & $532(16.1 \%)$ & $299(21.2 \%)$ \\
\hline \multicolumn{9}{|l|}{ Medication, $n(\%)$} \\
\hline Antidiabetic therapy & $0(0.0 \%)$ & $0(0.0 \%)$ & $0(0.0 \%)$ & $0(0.0 \%)$ & $12,261(79.8 \%)$ & $2232(82.8 \%)$ & $2755(83.4 \%)$ & $1232(87.3 \%)$ \\
\hline Diuretics & $1005(27.1 \%)$ & $198(30.7 \%)$ & $240(32.6 \%)$ & $110(32.6 \%)$ & $3664(23.8 \%)$ & $745(27.6 \%)$ & $1123(34.0 \%)$ & $542(38.4 \%)$ \\
\hline Beta-blockers & $473(12.8 \%)$ & $91(14.1 \%)$ & $239(32.5 \%)$ & $107(31.8 \%)$ & $1918(12.5 \%)$ & $385(14.3 \%)$ & $1436(43.5 \%)$ & $542(38.4 \%)$ \\
\hline Calcium channel blockers & $536(14.5 \%)$ & $108(16.7 \%)$ & $207(28.1 \%)$ & $109(32.3 \%)$ & $2655(17.3 \%)$ & $552(20.5 \%)$ & $1126(34.1 \%)$ & $494(35.0 \%)$ \\
\hline $\begin{array}{l}\text { Agents acting on the } \\
\text { renin-angiotensin system }\end{array}$ & $1956(52.8 \%)$ & $376(58.3 \%)$ & $461(62.6 \%)$ & $218(64.7 \%)$ & $9090(59.1 \%)$ & $1801(66.8 \%)$ & $2424(73.4 \%)$ & $1092(77.4 \%)$ \\
\hline Other antihypertensives & $125(3.4 \%)$ & $35(5.4 \%)$ & $35(4.8 \%)$ & $18(5.3 \%)$ & $675(4.4 \%)$ & $161(6.0 \%)$ & $229(6.9 \%)$ & $100(7.1 \%)$ \\
\hline Statins & $1189(32.1 \%)$ & $232(36.0 \%)$ & $461(62.6 \%)$ & $213(63.2 \%)$ & $7448(48.4 \%)$ & $1383(51.3 \%)$ & $2456(74.3 \%)$ & $1037(73.5 \%)$ \\
\hline Other lipid-lowering agents & $137(3.7 \%)$ & $30(4.7 \%)$ & $41(5.6 \%)$ & $27(8.0 \%)$ & $1046(6.8 \%)$ & $178(6.6 \%)$ & $378(11.4 \%)$ & $158(11.2 \%)$ \\
\hline Aspirin & $378(10.2 \%)$ & $136(21.1 \%)$ & $440(59.8 \%)$ & $197(58.5 \%)$ & $4348(28.3 \%)$ & $926(34.3 \%)$ & $2272(68.8 \%)$ & $939(66.5 \%)$ \\
\hline Follow-up, years, IQR & $5.8(4.7,7.5)$ & $5.7(4.6,7.2)$ & $5.7(4.6,7.2)$ & $5.5(4.5,6.9)$ & $5.9(4.8,7.3)$ & $5.6(4.6,7.1)$ & $5.6(4.6,7.1)$ & $5.4(4.4,7.0)$ \\
\hline Lost to follow-up, $n(\%)$ b & $58(1.6 \%)$ & $9(1.4 \%)$ & $8(1.1 \%)$ & $6(1.8 \%)$ & $220(1.4 \%)$ & $52(1.9 \%)$ & $50(1.5 \%)$ & $18(1.3 \%)$ \\
\hline
\end{tabular}

Abbreviations: ABI, ankle-brachial index; BP, blood pressure; COPD, chronic obstructive pulmonary disease; CVD, cardiovascular disease; HDL, high density lipoprotein; LDL, low density lipoprotein; n, number of persons. Values are mean (standard deviation), unless otherwise specified. ${ }^{a} \mathrm{ABI}<0.9$. ${ }^{\mathrm{b}}$ With respect to the number of participants in that group. 
Table A6. Raw incidences of all-cause mortality, acute myocardial infarction, and ischemic stroke by population groups. Complete cases.

\begin{tabular}{|c|c|c|c|c|c|c|c|c|}
\hline \multicolumn{3}{|c|}{ Group } & \multicolumn{2}{|c|}{ All-Cause Mortality } & \multicolumn{2}{|c|}{ Acute Myocardial Infarction } & \multicolumn{2}{|r|}{ Stroke } \\
\hline Diabetes & CVD & Low $\mathrm{ABI}^{\mathrm{a}}$ & Events $b$ & Incidence Rate ${ }^{c}(95 \%$ CI $)$ & Events & Incidence Rate (95\% CI) & Events & Incidence Rate $(95 \% \mathrm{CI})$ \\
\hline Yes & Yes & Yes & 406 & $53.0(48.0,58.4)$ & 153 & $21.0(17.9,24.6)$ & 229 & $32.5(28.5,36.9)$ \\
\hline Yes & Yes & No & 648 & $34.5(32.0,37.3)$ & 248 & $13.7(12.1,15.5)$ & 445 & $25.3(23.1,27.8)$ \\
\hline Yes & No & Yes & 428 & $27.7(25.2,30.5)$ & 94 & $6.2(5.0,7.6)$ & 188 & $12.5(10.9,14.5)$ \\
\hline No & Yes & Yes & 69 & $36.4(28.7,46.1)$ & 18 & $9.8(6.2,15.6)$ & 38 & $21.4(15.5,29.4)$ \\
\hline No & Yes & No & 124 & $29.2(24.5,34.9)$ & 31 & $7.4(5.2,10.6)$ & 58 & $14.2(11.0,18.4)$ \\
\hline No & No & Yes & 86 & $23.0(18.6,28.4)$ & 22 & $6.0(3.9,9.1)$ & 34 & $9.3(6.6,13.0)$ \\
\hline No & No & No & 260 & $11.6(10.3,13.1)$ & 59 & $2.7(2.1,3.4)$ & 132 & $6.0(5.1,7.1)$ \\
\hline
\end{tabular}

${ }^{a} \mathrm{ABI}<0.9 .{ }^{\mathrm{b}}$ Number of events. ${ }^{\mathrm{c}}$ Expressed per 1000 person-years. ABI indicates ankle-brachial index; CI, confidence interval; CVD, cardiovascular disease.

Table A7. Adjusted hazard ratios (95\% confidence intervals) for all-cause mortality, acute myocardial infarction, and ischemic stroke, by groups. Complete cases.

\begin{tabular}{cccccc}
\hline & Group & & \multicolumn{3}{c}{ HR (95\% Confidence Interval) } \\
\hline Diabetes & CVD & Low ABI a & All-Cause Mortality & AMI & Ischemic Stroke \\
\hline Yes & Yes & Yes & $2.74(2.32,3.24)$ & $4.51(3.26,6.23)$ & $3.89(3.09,4.89)$ \\
Yes & Yes & No & $2.08(1.78,2.42)$ & $3.28(2.41,4.46)$ & $3.38(2.74,4.17)$ \\
Yes & No & Yes & $2.11(1.81,2.47)$ & $1.83(1.31,2.54)$ & $1.87(1.49,2.34)$ \\
No & Yes & Yes & $1.58(1.21,2.07)$ & $1.96(1.14,3.36)$ & $2.44(1.69,3.53)$ \\
No & Yes & No & $1.66(1.34,2.07)$ & $1.98(1.27,3.10)$ & $1.85(1.35,2.54)$ \\
No & No & Yes & $1.54(1.21,1.97)$ & $1.76(1.08,2.88)$ & $1.32(0.90,1.92)$ \\
Yes & No & No & $1.52(1.33,1.74)$ & $1.47(1.11,1.94)$ & $1.44(1.19,1.74)$ \\
No & No & No & Reference & Reference & Reference \\
\hline
\end{tabular}

Abbreviations: ABI, ankle-brachial index; AMI, acute myocardial infarction; CVD, cardiovascular disease. ${ }^{\text {a }} \mathrm{ABI}<0.9$. 


\section{References}

1. Rosamond, W.D.; Chambless, L.E.; Heiss, G.; Mosley, T.H.; Coresh, J.; Whitsel, E.; Wagenknecht, L.; Ni, H.; Folsom, A.R. Twenty-two-year trends in incidence of myocardial infarction, coronary heart disease mortality, and case fatality in 4 US communities, 1987-2008. Circulation 2012, 125, 1848-1857. [CrossRef] [PubMed]

2. Wang, H.; Naghavi, M.; Allen, C.; Barber, R.M.; Carter, A.; Casey, D.C.; Charlson, F.J.; Chen, A.Z.; Coates, M.M.; Coggeshall, M.; et al. Global, regional, and national life expectancy, all-cause mortality, and cause-specific mortality for 249 causes of death, 1980-2015: A systematic analysis for the Global Burden of Disease Study 2015. Lancet 2016, 388, 1459-1544. [CrossRef]

3. Goff, D.C.; Lloyd-Jones, D.M.; Bennett, G.; Coady, S.; D'Agostino, R.B.; Gibbons, R.; Greenland, P.; Lackland, D.T.; Levy, D.; O'Donnell, C.J.; et al. 2013 ACC/AHA guideline on the assessment of cardiovascular risk: A report of the American college of cardiology/American heart association task force on practice guidelines. Circulation 2014, 129. [CrossRef] [PubMed]

4. Stone, N.J.; Robinson, J.G.; Lichtenstein, A.H.; Bairey Merz, C.N.; Blum, C.B.; Eckel, R.H.; Goldberg, A.C.; Gordon, D.; Levy, D.; Lloyd-Jones, D.M.; et al. 2013 ACC/AHA guideline on the treatment of blood cholesterol to reduce atherosclerotic cardiovascular risk in adults: A report of the American college of cardiology/American heart association task force on practice guidelines. J. Am. Coll. Cardiol. 2014, 63, 2889-2934. [CrossRef] [PubMed]

5. Conroy, R.M.; Pyörälä, K.; Fitzgerald, A.P.; Sans, S.; Menotti, A.; De Backer, G.; De Bacquer, D.; Ducimetière, P.; Jousilahti, P.; Keil, U.; et al. Estimation of ten-year risk of fatal cardiovascular disease in Europe: The SCORE project. Eur. Heart J. 2003, 24, 987-1003. [CrossRef]

6. Marrugat, J.; Subirana, I.; Ramos, R.; Vila, J.; Marín-Ibañez, A.; Guembe, M.J.; Rigo, F.; Tormo Díaz, M.J.; Moreno-Iribas, C.; Cabré, J.J.; et al. Derivation and validation of a set of 10-year cardiovascular risk predictive functions in Spain: The FRESCO Study. Prev. Med. 2014, 61, 66-74. [CrossRef] [PubMed]

7. Piepoli, M.F. 2016 European Guidelines on cardiovascular disease prevention in clinical practice. Int. J. Behav. Med. 2017, 24, 321-419. [CrossRef]

8. Aboyans, V.; Criqui, M.H.; Abraham, P.; Allison, M.A.; Creager, M.A.; Diehm, C.; Fowkes, F.G.R.; Hiatt, W.R.; Jönsson, B.; Lacroix, P.; et al. Measurement and interpretation of the Ankle-Brachial Index: A scientific statement from the American Heart Association. Circulation 2012, 126, 2890-2909. [CrossRef]

9. Aboyans, V.; Ricco, J.-B.; Bartelink, M.-L.E.L.; Björck, M.; Brodmann, M.; Cohnert, T.; Collet, J.-P.; Czerny, M.; De Carlo, M.; Debus, S.; et al. 2017 ESC Guidelines on the Diagnosis and Treatment of Peripheral Arterial Diseases, in collaboration with the European Society for Vascular Surgery (ESVS). Eur. Heart J. 2018. [CrossRef]

10. Fowkes, F.G.R.; Murray, G.D.; Butcher, I.; Heald, C.L.; Lee, R.J.; Chambless, L.E.; Folsom, A.R.; Hirsch, A.T.; Dramaix, M.; DeBacker, G.; et al. Ankle brachial index combined with Framingham Risk Score to predict cardiovascular events and mortality: A meta-analysis. JAMA 2008, 300, 197-208.

11. Hanssen, N.M.J.; Huijberts, M.S.; Schalkwijk, C.G.; Nijpels, G.; Dekker, J.M.; Stehouwer, C.D.A. Associations between the ankle-brachial index and cardiovascular and all-cause mortality are similar in individuals without and with type 2 diabetes: Nineteen-year follow-up of a population-based cohort study. Diabetes Care 2012, 35, 1731-1735. [CrossRef] [PubMed]

12. Wang, Y.; Mou, Q.; Zhao, D.; Xu, Y.; Hu, D.; Ma, H.; Liu, J.; Guo, X.; Li, J. Predictive value of ankle-brachial index and blood glucose on the outcomes of six-year all-cause mortality and cardiovascular mortality in a Chinese population of type 2 diabetes patients. Int. Angiol. 2012, 31, 586-594. [PubMed]

13. Banerjee, S.; Vinas, A.; Mohammad, A.; Hadidi, O.; Thomas, R.; Sarode, K.; Banerjee, A.; Garg, P.; Weideman, R.A.; Little, B.B.; et al. Significance of an Abnormal Ankle-Brachial Index in Patients With Established Coronary Artery Disease With and Without Associated Diabetes Mellitus. Am. J. Cardiol. 2014, 113, 1280-1284. [CrossRef] [PubMed]

14. del Mar García-Gil, M.; Hermosilla, E.; Prieto-alhambra, D.; Fina, F.; Rosell, M.; Williams, T. Construction and validation of a scoring system for the selection of high-quality data in a Spanish population primary care database (SIDIAP). Inform. Prim. Care 2011, 19, 135-145. [CrossRef]

15. Ramos, R.; Balló, E.; Marrugat, J.; Elosua, R.; Sala, J.; Grau, M.; Vila, J.; Bolíbar, B.; García-Gil, M.; Martí, R.; et al. Validity for use in research on vascular diseases of the SIDIAP (Information System for the Development of Research in Primary Care): The EMMA study. Rev. Esp. Cardiol. 2012, 65, 29-37. [CrossRef] 
16. SIDIAP (ES). Barcelona: SIDIAP (ES). Available online: http://www.sidiap.org/index.php/difusiomenu/ articles (accessed on 27 March 2017).

17. Ponjoan, A.; García-Gil, M.M.; Martí, R.; Comas-Cufí, M.; Alves-I-Cabratosa, L.; Sala, J.; Marrugat, J.; Elosua, R.; de Tuero, G.C.; Grau, M.; et al. Derivation and validation of BOREAS, a risk score identifying candidates to develop cold-induced hypertension. Environ. Res. 2014, 132C, 190-196. [CrossRef]

18. García-Gil, M.; Blanch, J.; Comas-Cufí, M.; Daunis-i-Estadella, J.; Bolíbar, B.; Martí, R.; Ponjoan, A.; Alves-Cabratosa, L.; Ramos, R. Patterns of statin use and cholesterol goal attainment in a high-risk cardiovascular population: A retrospective study of primary care electronic medical records. J. Clin. Lipidol. 2016, 10, 134-142. [CrossRef]

19. Ramos, R.; García-Gil, M.; Comas-Cufí, M.; Quesada, M.; Marrugat, J.; Elosua, R.; Sala, J.; Grau, M.; Martí, R.; Ponjoan, A.; et al. Statins for Prevention of Cardiovascular Events in a Low-Risk Population with Low Ankle Brachial Index. J. Am. Coll. Cardiol. 2016, 67, 630-640. [CrossRef]

20. Potier, L.; Roussel, R.; Labreuche, J.; Marre, M.; Cacoub, P.; Röther, J.; Wilson, P.W.; Goto, S.; Bhatt, D.L.; Steg, P.G. Interaction between diabetes and a high ankle-brachial index on mortality risk. Eur. J. Prev. Cardiol. 2015, 22, 615-621. [CrossRef]

21. Marrugat, J.; Vila, J.; Baena-Díez, J.M.; Grau, M.; Sala, J.; Ramos, R.; Subirana, I.; Fitó, M.; Elosua, R. Relative validity of the 10-year cardiovascular risk estimate in a population cohort of the REGICOR study. Rev. Española Cardiol. 2011, 64, 385-394. [CrossRef]

22. Hippisley-Cox, J.; Coupland, C.; Vinogradova, Y.; Robson, J.; Minhas, R.; Sheikh, A.; Brindle, P. Predicting cardiovascular risk in England and Wales: Prospective derivation and validation of QRISK2. BMJ 2008, 336, 1475-1482. [CrossRef] [PubMed]

23. Pasqualini, L.; Schillaci, G.; Pirro, M.; Vaudo, G.; Leli, C.; Colella, R.; Innocente, S.; Ciuffetti, G.; Mannarino, E. Prognostic value of low and high ankle-brachial index in hospitalized medical patients. Eur. J. Intern. Med. 2012, 23, 240-244. [CrossRef] [PubMed]

24. Nishimura, H.; Miura, T.; Minamisawa, M.; Ueki, Y.; Abe, N.; Hashizume, N.; Mochidome, T.; Harada, M.; Shimizu, K.; Shoin, W.; et al. Clinical characteristics and outcomes of patients with high ankle-brachial index from the IMPACT-ABI study. PLOS ONE 2016, 11, 1-12. [CrossRef] [PubMed]

25. Criqui, M.H.; McClelland, R.L.; McDermott, M.M.; Allison, M.A.; Blumenthal, R.S.; Aboyans, V.; Ix, J.H.; Burke, G.L.; Liu, K.; Shea, S. The ankle-brachial index and incident cardiovascular events in the MESA (Multi-Ethnic study of atherosclerosis). J. Am. Coll. Cardiol. 2010, 56, 1506-1512. [CrossRef] [PubMed]

26. Elosua-Bayés, M.; Martí-Lluch, R.; del Mar García-Gil, M.; Camós, L.; Comas-Cufí, M.; Blanch, J.; Ponjoan, A.; Alves-Cabratosa, L.; Elosua, R.; Grau, M.; et al. Association of Classic Cardiovascular Risk Factors and Lifestyles With the Cardio-ankle Vascular Index in a General Mediterranean Population. Rev. Española Cardiol. 2018, 71, 458-465.

27. Janssen, K.J.M.; Donders, A.R.; Harrell, F.E., Jr.; Vergouwe, Y.; Chen, Q.; Grobbee, D.E.; Moons, K.G.M. Missing covariate data in medical research: To impute is better than to ignore. J. Clin. Epidemiol. 2010, 63, 721-727. [CrossRef] [PubMed]

28. White, I.R.; Royston, P.; Wood, A.M. Multiple imputation using chained equations: Issues and guidance for practice. Stat. Med. 2011, 30, 377-399. [CrossRef] [PubMed]

29. Sterne, J.A.; White, I.R.; Carlin, J.B.; Spratt, M.; Royston, P.; Kenward, M.G.; Wood, A.M.; Carpenter, J.R. Multiple imputation for missing data in epidemiological and clinical research: Potential and pitfalls. BMJ 2009, 338, b2393. [CrossRef] [PubMed]

30. Team R Development Core R: A Language and Environment for Statistical Computing. Available online: http://www.r-project.org/ (accessed on 10 May 2019).

31. van Buuren, S.; Groothuis-Oudshoorn, K. mice: Multivariate Imputation by Chained Equations in R. J. Stat. Softw. 2011, 45, 1-67. [CrossRef]

32. Samba, H.; Guerchet, M.; Ndamba-Bandzouzi, B.; Kehoua, G.; Mbelesso, P.; Desormais, I.; Aboyans, V.; Preux, P.-M.; Lacroix, P. Ankle Brachial Index (ABI) predicts 2-year mortality risk among older adults in the Republic of Congo: The EPIDEMCA-FU study. Atherosclerosis 2019, 286, 121-127. [CrossRef]

33. Otsuka, K.; Nakanishi, K.; Shimada, K.; Nakamura, H.; Inanami, H.; Nishioka, H.; Fujimoto, K.; Kasayuki, N.; Yoshiyama, M. Ankle-brachial index, arterial stiffness, and biomarkers in the prediction of mortality and outcomes in patients with end-stage kidney disease. Clin. Cardiol. 2019. [CrossRef] [PubMed] 
34. Le Bivic, L.; Magne, J.; Guy-Moyat, B.; Wojtyna, H.; Lacroix, P.; Blossier, J.-D.; Le Guyader, A.; Desormais, I.; Aboyans, V. The intrinsic prognostic value of the ankle-brachial index is independent from its mode of calculation. Vasc. Med. 2019, 24, 23-31. [CrossRef] [PubMed]

35. Miura, T.; Soga, Y.; Doijiri, T.; Aihara, H.; Yokoi, H.; Iwabuchi, M.; Nobuyoshi, M. Prevalence and Clinical Outcome of Polyvascular Atherosclerotic Disease in Patients Undergoing Coronary Intervention. Circ. J. 2013, 77, 89-95. [CrossRef] [PubMed]

36. Jönelid, B.; Johnston, N.; Berglund, L.; Andrén, B.; Kragsterman, B.; Christersson, C. Ankle brachial index most important to identify polyvascular disease in patients with non-ST elevation or ST-elevation myocardial infarction. Eur. J. Intern. Med. 2016, 30, 55-60. [CrossRef] [PubMed]

37. Gerhard-Herman, M.D.; Gornik, H.L.; Barrett, C.; Barshes, N.R.; Corriere, M.A.; Drachman, D.E.; Fleisher, L.A.; Fowkes, F.G.R.; Hamburg, N.M.; Kinlay, S.; et al. 2016 AHA/ACC Guideline on the Management of Patients With Lower Extremity Peripheral Artery Disease: A Report of the American College of Cardiology/American Heart Association Task Force on Clinical Practice Guidelines. J. Am. Coll. Cardiol. 2017, 69, e71-e126. [CrossRef] [PubMed]

38. US Preventive Services Task Force; Curry, S.J.; Krist, A.H.; Owens, D.K.; Barry, M.J.; Caughey, A.B.; Davidson, K.W.; Doubeni, C.A.; Epling, J.W.; Kemper, A.R.; et al. Screening for Peripheral Artery Disease and Cardiovascular Disease Risk Assessment With the Ankle-Brachial Index: US Preventive Services Task Force Recommendation Statement. JAMA 2018, 320, 177-183. [CrossRef]

39. Olin, J.W.; Halperin, J.L. Viewpoint US Preventive Services Task Force recommendation statement regarding screening for peripheral artery disease with the ankle-brachial index: Déjà vu all over again. Lancet 2018, 392, 1160-1162. [CrossRef]

40. Lindholt, J.S.; Søgaard, R. Population screening and intervention for vascular disease in Danish men (VIVA): A randomised controlled trial. Lancet 2017, 390, 2256-2265. [CrossRef]

41. Ramos, R.; Baena-Díez, J.M.; Quesada, M.; Solanas, P.; Subirana, I.; Sala, J.; Alzamora, M.; Forès, R.; Masiá, R.; Elosua, R.; et al. Derivation and validation of REASON: A risk score identifying candidates to screen for peripheral arterial disease using ankle brachial index. Atherosclerosis 2011, 214, 474-479. [CrossRef]

42. Sigvant, B.; Lundin, F.; Wahlberg, E. The Risk of Disease Progression in Peripheral Arterial Disease is Higher than Expected: A Meta-Analysis of Mortality and Disease Progression in Peripheral Arterial Disease. Eur. J. Vasc. Endovasc. Surg. 2016, 51, 395-403. [CrossRef]

43. Schramm, T.K.; Gislason, G.H.; Køber, L.; Rasmussen, S.; Rasmussen, J.N.; Abildstrøm, S.Z.; Hansen, M.L.; Folke, F.; Buch, P.; Madsen, M.; et al. Diabetes patients requiring glucose-lowering therapy and nondiabetics with a prior myocardial infarction carry the same cardiovascular risk: A population study of 3.3 million people. Circulation 2008, 117, 1945-1954. [CrossRef] [PubMed]

44. Whiteley, L.; Padmanabhan, S.; Hole, D.; Isles, C. Should diabetes be considered a coronary heart disease risk equivalent?: Results from 25 years of follow-up in the Renfrew and Paisley survey. Diabetes Care 2005, 28, 1588-1593. [CrossRef] [PubMed]

45. Mukamal, K.J.; Nesto, R.W.; Cohen, M.C.; Muller, J.E.; Maclure, M.; Sherwood, J.B.; Mittleman, M.A. Impact of diabetes on long-term survival after acute myocardial infarction: Comparability of risk with prior myocardial infarction. Diabetes Care 2001, 24, 1422-1427. [CrossRef] [PubMed]

46. Haffner, S.M.; Lehto, S.; Rönnemaa, T.; Pyörälä, K.; Laakso, M. Mortality from coronary heart disease in subjects with type 2 diabetes and in nondiabetic subjects with and without prior myocardial infarction. N. Engl. J. Med. 1998, 339, 229-234. [CrossRef] [PubMed]

47. Evans, J.M.M.; Wang, J.; Morris, A.D.; Stamler, J.; Vaccaro, O.; Neaton, J.; Wentworth, D.; Stratton, I.; Adler, A.; Neil, A.; et al. Comparison of cardiovascular risk between patients with type 2 diabetes and those who had had a myocardial infarction: Cross sectional and cohort studies. BMJ 2002, 324, 939-942. [CrossRef]

48. Bulugahapitiya, U.; Siyambalapitiya, S.; Sithole, J.; Idris, I. Is diabetes a coronary risk equivalent? Systematic review and meta-analysis. Diabet. Med. 2009, 26, 142-148. [CrossRef]

49. Mondesir, F.L.; Brown, T.M.; Muntner, P.; Durant, R.W.; Carson, A.P.; Safford, M.M.; Levitan, E.B. Diabetes, diabetes severity, and coronary heart disease risk equivalence: REasons for Geographic and Racial Differences in Stroke (REGARDS). Am. Heart J. 2016, 181, 43-51. [CrossRef]

50. Hu, F.B.; Stampfer, M.J.; Solomon, C.G.; Liu, S.; Willett, W.; Speizer, F.; Nathan, D.; Manson, J. THe Impact of Diabetes Mellitus on Mortality From All Causes and Coronary Heart Disease in Women. JAMA Intern. Med. 2001, 161, 1717-1723. [CrossRef] 
51. Papanas, N.; Symeonidis, G.; Mavridis, G.; Georgiadis, G.S.; Papas, T.T.; Lazarides, M.K.; Maltezos, E. Ankle-brachial index: A surrogate marker of microvascular complications in type 2 diabetes mellitus? Int. Angiol. 2007, 26, 253-257.

52. Greenland, P.; Alpert, J.S.; Beller, G.A.; Benjamin, E.J.; Budoff, M.J.; Fayad, Z.A.; Foster, E.; Hlatky, M.A.; Hodgson, J.M.; Kushner, F.G.; et al. 2010 ACCF/AHA guideline for assessment of cardiovascular risk in asymptomatic adults: Executive summary. J. Am. Coll. Cardiol. 2010, 56, 2182-2199. [CrossRef]

53. Goff, D.C., Jr.; Lloyd-Jones, D.M.; Bennett, G.; Coady, S.; D'Agostino, R.B.; Gibbons, R.; Greenland, P.; Lackland, D.T.; Levy, D.; O'Donnell, C.J.; et al. 2013 ACC/AHA Guideline on the Assessment of Cardiovascular Risk: A Report of the American College of Cardiology/American Heart Association Task Force on Practice Guidelines. J. Am. Coll. Cardiol. 2014, 63, 2935-2959. [CrossRef] [PubMed]

54. Piepoli, M.F.; Hoes, A.W.; Brotons, C.; Hobbs, R.F.D.; Corra, U. Main messages for primary care from the 2016 European Guidelines on cardiovascular disease prevention in clinical practice. Eur. J. Gen. Pract. 2018, 24, 51-56. [CrossRef] [PubMed]

55. Rydén, L.; Grant, P.J.; Anker, S.D.; Berne, C.; Cosentino, F.; Danchin, N.; Deaton, C.; Escaned, J.; Hammes, H.-P.; Huikuri, H.; et al. ESC Guidelines on diabetes, pre-diabetes, and cardiovascular diseases developed in collaboration with the EASD: The Task Force on diabetes, pre-diabetes, and cardiovascular diseases of the European Society of Cardiology (ESC) and developed in collaboratio. Eur. Heart J. 2013, 34, 3035-3087. [PubMed]

(C) 2019 by the authors. Licensee MDPI, Basel, Switzerland. This article is an open access article distributed under the terms and conditions of the Creative Commons Attribution (CC BY) license (http://creativecommons.org/licenses/by/4.0/). 